\title{
LA POSIBILIDAD DE DESOBEDIENCIA A LA DISPOSICIÓN INJUSTA EN FRANCISCO SUÁREZ
}

\author{
Sebastián Pierpauli \\ PPGFIL - PUC - Buenos Aires
}

\begin{abstract}
The purpose of this study is to analyze the possibility of human disobedience to the law in the thought of Francisco Suárez. The particularity of our research is that we have focused on the De legibus (1612) preceding the Defensio Fidei (1613) in which this work deals specifically with regard to the eminent resistance and disobedience to the tyrant. However, we have been concerned to inquire into the problem proposed in De Legibus without ignoring the specific treatment in Defensie Fidei, which has already been the subject of numerous investigations. First expose some issues that lead to the main problem of this work. Thus we refer to the just laws and unjust as Suárez. Then the social basis of the necessity of positive laws and civil authorities, and the common good as one of the main purposes to be pursued by human law. In the final part of this study demonstrate that we are interested only when the conditions fail to be met by the law, is that the eminent admits disobedience to unjust rule, therefore, loses its status as law.
\end{abstract}

Keywords: desobedience, tirany, sociability, common good.

Resumo: 0 propósito do presente estudo é analisar a possibilidade de desobediência à lei humana no pensamento de Francisco Suárez. A particulariadade de nossa investigação radica em que centramos a análise em De legibus (1612), que precede a Defensio Fidei (1613), obra esta em que $O$ Eximio trata concretamente da questão atinente à resistência e à desobediência ao tirano. Todavia, interessa-nos indagar sobre o problema proposto em De Legibus, sem desconhecer o tratamento específico em Defensio Fidei, o qual tem sido objeto de numerosas investigações. Primeiramente exporemos algumas questões que desembocam no problema principal desse trabalho. Assim, referimo-nos às leis justas e injustas segundo Suárez; logo à sociabilidade como fundamento da necessidade de leis positivas e das autoridades civis, tanto quanto ao bem comum como um dos principais fins que a lei humana deve perseguir. Na parte final deste trabalho interessa-nos demonstrar 
que, somente quando faltam as condições que a lei deve reunir, é que $O$ Eximio admite a desobediência à norma injusta, a qual, por esse motivo, perde sua condicição de lei.

Palavras-chave: desobediencia, tirania, sociabilidade, bem comum.

\section{Introducción.}

El propósito del presente trabajo es analizar un nuevo aspecto en el pensamiento de Francisco Suárez a los efectos de determinar el lugar que debe ocupar el autor como nexo entre el pensamiento medieval y el moderno. Interesa aquí analizar la cuestión de la obediencia y la desobediencia a la ley humana en Francisco Suárez en el De Legibus y, a partir de allí, extraer algunas conclusiones respecto del pensamiento del Doctor Eximio. Una pregunta inicial podría ser ¿Admite Suárez la desobediencia a la ley humana? En principio este tema se vuelve más que interesante en función de que no parece haberse dedicado Suárez en la obra mencionada específicamente a esta cuestión. Creemos resulta fundamental conocer primeramente lo que sobre este problema ha sostenido el Aquinate en la medida en que Suárez se muestra como su seguidor. Por este motivo la doctrina de Suárez deberá tener en la de Tomás de Aquino su obligado contraste.

Resulta relevante indagar los motivos por los que Suárez no ha dedicado un capítulo especial a la cuestión de la desobediencia a la ley humana, como sí lo ha hecho con otros asuntos. Sí ha tratado Suárez sobre el derecho de resistencia al tirano efectuando una diferenciación entre aquel que es tirano desde su origen, por el modo de acceso al poder, y aquel que lo es por su ejercicio. Pero esto no es lo mismo que desobediencia a la ley. Con la desobediencia a la ley el gobernante no deja de ser gobernante. En cambio en el caso del derecho de resistencia el fin primordial de tal acto es el derrocamiento del tirano y claro está existe la posibilidad de desobediencia por encontrarnos con algunas causas comunes entre desobediencia civil y derecho de resistencia. ${ }^{1}$

Nos preguntábamos los motivos porque Suárez no trata específicamente sobre la desobediencia a la ley humana. Esta pregunta no

\footnotetext{
1 Un tratamiento prolijo sobre la cuestión de la tiranía en el pensamiento de Suárez puede verse en Gallegos Rocafull J.M, La doctrina política del P. Francisco Suárez. Editorial Ius, México. 1948. Ps. 77 a 82. En el mismo sentido un trabajo interesante en el que se trata sobre este mismo asunto es el de Castaño S. R. Los principios de legitimidad en Suárez, su recepción y reelaboración de la doctrina aristotélica. Artículo, publicado en Ius Publicum n² 21, Santiago de Chile, 2008.
} 
encuentra respuesta hoy para nosotros. Sin embargo, cabe preguntarse iel hecho de que Suárez no se haya detenido específicamente en la cuestión de la desobediencia puede significar que no la admitió? Sobre esta cuestión nos interesa realizar nuestro aporte. Así pues, aun cuando Suárez no analizó el tema de la desobediencia a la ley humana en profundidad sí lo ha tratado en diversas partes de su obra, como veremos, a propósito de otras cuestiones sobre la ley humana.

\section{La cuestión de las leyes justas e injustas en Suárez.}

Hemos dicho que Suárez no dedicó un capítulo especial de su vasta obra a la cuestión de la posibilidad de desobediencia a la ley humana. Sin embargo el tema aquí propuesto se encuentra de algún modo tratado y distribuido a lo largo de diversas partes del De legibus.

De este modo pensamos que en primer lugar, resulta fundamental analizar la cuestión de la ley justa e injusta en Francisco Suárez. Ello nos permitirá deducir en importante medida el pensamiento de nuestro autor $\mathrm{y}$, a su vez, determinar el momento histórico con el que se encuentra más afín.

Al igual que para Aristóteles y Tomás de Aquino existe en Suárez una identificación entre los conceptos derecho y justicia. Este constituye uno de los asuntos que primeramente trata Suárez en el comienzo del De Legibus. Así pues se pregunta: ¿Cuál es la propia y verdadera ley? Y al respecto sostiene: "aunque a veces suelen designarse con el nombre de ley los preceptos o reglas injustas hablando en sentido propio y absoluto, solamente puede llamarse ley la que es medida de la rectitud sin más y, consiguientemente, sólo la que es regla recta y honesta".2 Nuevamente nuestro autor se apoya en la doctrina de Tomás de Aquino ${ }^{3}$ en primer lugar y luego Agustín de Hipona ${ }^{4}$, Cicerón ${ }^{5}$ y Platón ${ }^{6}$. Es decir, en los autores que citamos existe comunidad de pensamiento en cuanto sólo puede llamarse ley la que es justa. En otros términos: el axioma "non videtur esse lex quae iusta

2 Suárez Francisco. Tractatus de Legibus ac Deo Legislatore I,I,6: "Licet (inquam) hoc ita sit, nihilominus proprie et simpliciter loquendo, sola illa, quae est mensura rectitudinis simpliciter, et consequenter sola illa, quae est regula recta et honesta potest lex apellari". Versión Española por José Ramón Eguillor Muniozguren, S.I. Madrid. 1967. En adelante nos referiremos a esta obra bajo la abreviación DL.

${ }^{3}$ Tomás de Aquino. Summa Theologiae (A partir de ahora STh), I- II Q. 90 a.1 y Q. 96 a.4. Torino,1999.

${ }^{4}$ Agustín de Hipona, De Libero arbitrio, Madrid, Bac, 1971, L,I C. 5.

${ }^{5}$ Las Leyes, Intituto de estudios políticos, Madrid, 1970. Traducción de Alvaro D Ors. L II, 5,11.

${ }^{6}$ Diálogo Minos o de la ley. 
non fuerit" ${ }^{7}$ une el pensamiento de los autores recientemente mencionados. A su vez, ello implica que en el mismo Suárez existe la concreta posibilidad de determinar objetivamente qué es justo y qué injusto. Esto lo aleja considerablemente de algunos representantes del pensamiento moderno para los cuales el juicio sobre lo justo e injusto es siempre algo subjetivo e influenciado por factores emocionales y por tanto carente de racionalidad. ${ }^{8}$ Desde este punto de vista el pensamiento de Suárez resulta irreconciliable con el de Hans Kelsen, por mencionar un ejemplo. Existe en definitiva en el jesuita granadino, y en los autores a los que adhiere, una negación de la condición de ley de aquella que es injusta y ello se basa en que todos ellos coinciden en la existencia de una concreta posibilidad de percepción objetiva de aquello que es justo o injusto. Esa percepción común encuentra como fundamento la existencia de una semejanza entre todos los hombres, como afirma Cicerón, respecto de sus opiniones o sensaciones. ${ }^{9}$ Es decir, contrariamente al pensamiento escéptico, existen realidades que son captadas del mismo modo por todos y aun en diferentes momentos históricos y por ello se descarta absolutamente un relativismo absoluto. Se parte de una concepción según la cual la existencia de diversas percepciones de lo que es justo o injusto, bueno o malo, en los diferentes tiempos y pueblos, no se debe a un punto de partida escéptico respecto de las cosas o a una imposibilidad de definir lo que es justo o injusto, sino que ello puede deberse a un cambio en las costumbres o la corrupción de las mismas que altera el modo correcto de observar las cosas. De allí se entiende el ejemplo de Tomás

\footnotetext{
${ }^{7}$ Agustín de Hipona, Op. cit. en nota 5 y La Ciudad de Dios, Vol. 2, Madrid, Bac, 1965, L..19 C.21.

8 Un ejemplo lo encontramos en Kelsen quien sostiene esta idea en la Teoría pura del Derecho, Ed. Eudeba, $4^{\mathrm{a}}$.ed. $2^{\mathrm{a}}$ ed. reimp.- Buenos Aires, año 2003. p. 49. Es imposible determinar científicamente, es decir de manera racional y fundándose sobre la experiencia una definición de la noción de justicia. La misma idea se encuentra en la obra del mismo autor ¿Qué es la justicia? 3ra ed. Universidad Nacional de Córdoba. 1966. p. 19: La respuesta al problema aquí planteado es siempre un juicio que, a última hora, está determinado por factores emocionales $y$, por consiguiente, tiene un carácter eminentemente subjetivo. Esto significa que es válido únicamente para el sujeto que formula el juicio y, en este sentido, es relativo. En el mismo sentido Alf Ross. Sobre el derecho y la justicia, Eudeba, 5ta ed. 1994. p. 273: Afirmar que una norma es injusta, como hemos visto, no es más que la expresión emocional de una reacción desfavorable frente a ella. La declaración de que una norma es injusta no contiene ninguna característica real, ninguna referencia a algún criterio, ninguna argumentación. La ideología de la justicia no tiene, pues, cabida en un examen racional del valor de las normas.

${ }^{9}$ Cicerón. Las Leyes I,X,29: "Nada hay tan semejante, tan igual, a otra cosa como todos los hombres entre nosotros mismos. Si no fuera porque la corrupción de las costumbres y la variedad de opiniones tienden a viciar y a torcer en cierta dirección la debilidad de los espíritus, nadie sería tan parecido a sí mismo, como lo serían todos entre sí".
} 
de Aquino que toma de Julio Cesar ${ }^{10}$ según el cual entre los germanos, en otro tiempo, no se reputaba inicuo el latrocinio realizado fuera de los límites de la ciudad. ${ }^{11}$

El pensamiento de Suárez respecto de la "ley injusta" puede resumirse en lo siguiente:...no es ley sino que recibe el nombre de ley sólo por cierta analogía en cuanto que prescribe una determinada manera de obrar en orden a un fin. ${ }^{12}$ Pero, en todo caso, no se trata de una ley.

\section{La importancia y necesidad de la autoridad. El poder de los hombres para dar leyes. La sociabilidad como fundamento de la necesidad de autoridad y de las leyes que ella dicte.}

Analizar la importancia y necesidad de la autoridad adquiere relevancia en cuanto de allí se derivan algunas cuestiones que deben considerarse antes de tratar lo referido a la desobediencia a la ley. Esta necesidad e importancia es destacada en diversas partes del De Legibus y a propósito de diferentes temas.

Señala en primer lugar Suárez la necesidad de la autoridad. El fundamento de la existencia de aquella se encuentra en la condición de “animal social” del hombre. Al respecto afirma el Doctor Eximio: “...la multitud humana por un especial deseo o consentimiento general, se reúne en un cuerpo político con un vínculo de sociedad y para ayudarse mutuamente en orden a un fin político. ${ }^{13}$ Nuestro autor sostiene que el fundamento por el que se forma una comunidad encuentra su raíz en un "deseo natural". Es decir, esta tendencia a la unión entre los hombres, por medio de la cual se prestan mutua ayuda, constituye algo natural y común entre todos los hombres. Estas ideas de Suárez pueden verificarse por la misma experiencia que muestra la tendencia natural del hombre a unirse a otros. Y a fin de que dicha comunidad formada naturalmente alcance su fin deviene la necesidad de una cabeza -consequenter indiget uno capite- como

\footnotetext{
${ }^{10}$ De Bello Gallico - L.6 cap. 23: "Latrocinio nullam habent infamiam, quae extra fines cuiusque civitatis fiunt".

${ }^{11}$ S.Th. I-II Q. 94 a.4.

${ }_{12} \mathrm{DL}$ I,I,6: ..."participat nomen legis per quandam analogiam, quatenus in ordinem ad aliquem finem praescribit certum operandi modum".

${ }_{13} \mathrm{DL}$ III,II,4: Alio ergo modo consideranda est hominum multitudo, quatenus speciale voluntate, seu communi consensu in unum corpus politicum congregantur uno societatis vinculo, et ut mutuo se iuvent in ordine ad unum finem politicum...
} 
afirma Suárez en DL III,II,4. En concordancia con esta idea sostiene el jesuita granadino: "En una comunidad así, como tal, por la misma naturaleza de la cosa se da este poder, de tal manera que no está en manos de los hombres reunirse de esa forma e impedir este poder." ${ }^{14}$ Reforzando tales ideas continúa: "...si nos imaginamos que los hombres quisieran ambas cosas, a saber, reunirse en esa forma pero con la condición de no quedar sujetos a este poder, esa actitud sería contradictoria y no conseguirían nada; porque sin gobierno político o un ordenamiento hacia él no puede concebirse un cuerpo político: lo primero, porque la unidad de este cuerpo en gran parte resulta de la sujeción a un mismo régimen y a un poder superior; y lo segundo, porque en otro caso ese cuerpo no podría ser dirigido a un mismo fin y al bien común; por eso es contrario a la razón natural el que se dé una comunidad humana que se una en forma de un cuerpo político y que no tenga algún poder común al cual cada uno de los miembros de la comunidad esté obligado a obedecer;...”. ${ }^{15}$

Así pues, debemos destacar algunas ideas que deberán ser consideradas en relación con el tema propuesto para este trabajo. En primer lugar, la autoridad deviene necesaria para la comunidad política en cuanto es factor de mantenimiento de unidad en la misma. Es decir, las partes que forman el todo se mantienen unidas cuando se encuentran todas dirigidas por un poder superior. En segundo lugar, y esta idea será a nuestro entender fundamental, sin esa autoridad la comunidad no puede dirigirse a un mismo fin ni al bien común. Obsérvese nuevamente la introducción del Doctor Eximio del concepto bien común. En otras palabras Suárez afirma que con la obediencia a la autoridad se facilita la realización del bien común. ${ }^{16} \mathrm{Y}$, a su vez, la autoridad encuentra como una de sus obligaciones la realización de aquél bien. Esto deberá tenerse en cuenta a la hora de tratar específicamente sobre la desobediencia a la ley. Del mismo modo resulta necesario destacar que Suárez se refiere a la "Autoridad". Lo contrario a la autoridad será el poder usurpado y en consecuencia la falta de poder para dictar la ley. ${ }^{17}$ Es decir, la facultad para legislar resulta fundamental tanto como el contenido de la ley

\footnotetext{
14|bídem.

$15 \mathrm{lb}$.

${ }^{16}$ El bien común se constituye en una de las finalidades de la ley y en Suárez es un requisito esencial de la misma. El bien común como fin de la ley puede verse en Suárez, entre otros pasajes, en DL III,XXXI,2 y III,XXXIV,7 y concretamente es tratada la cuestión en DL I,VII.

${ }^{17}$ Este es uno de los modos de tiranía que refiere Suárez y que por ausencia de legítima autoridad permite la desobediencia.
} 
que dicte esa autoridad. Trataremos luego sobre esta cuestión. En tercer lugar, la necesidad de la autoridad y de ley y el poder de los hombres para dar leyes encuentra su fundamento en la condición de "animal sociabile" del hombre. Esto lo manifiesta Suárez del siguiente modo: "Homo est animal sociabile, naturam suam postulans vitam civilem, et communicationem cum aliis hominibus". 18 Es decir, la primera necesidad de la ley encuentra su fundamento en el carácter de "animal social" del hombre y de su naturaleza que le exige vida civil y comunicación con otros hombres. El mismo argumento aparece en De legibus, III,I,3 siguiendo la doctrina de Aristóteles ${ }^{19}$ y Tomás de Aquino ${ }^{20}$. El Eximio afirma allí: "el hombre es un animal social y natural y rectamente desea vivir en comunidad. Es decir: el hombre es un animal social y de una manera natural y recta tiende a vivir en comunidad. Por medio de este pasaje explica Suárez la necesidad de la ley, dada esa vida en comunidad y en respuesta a la pregunta de si tienen los hombres poder para crear leyes. Su respuesta es que tal clase de poder es conforme a la misma naturaleza en cuanto que es necesario para el buen gobierno de las comunidades humanas. ${ }^{21} \mathrm{Y}$ todo ello a fin de evitar la confusión o el desorden en la comunidad. ${ }^{22}$

En virtud de aquella natural tendencia de los hombres a unirse, hecho que define al hombre como "animal sociabile" es que, como afirmamos, deviene necesario un poder. Ahora bien esta necesidad natural de una autoridad constituye para el Doctor Eximio una nueva razón para obedecer la ley en cuanto todo poder proviene de Dios, como sostiene en DL III,III,2. Así pues, una vez admitida la necesidad natural de un poder, se pregunta Suárez ¿De dónde viene ese poder? ¿Quién lo dio? A propósito de lo que aquí se trata podrá verse la distancia que media entre nuestro autor y el pensamiento del contractualismo moderno. Al comenzar el estudio de esta cuestión explica Suárez lo que cree ser la "Communis et vera sententia". 23 Esta "vera sententia” significa que este poder lo da inmediatamente Dios como autor de la naturaleza, pero de tal manera que los hombres como que disponen la materia y forman el sujeto capaz de ese poder, y Dios como que

\footnotetext{
${ }^{18} \mathrm{DL} \mathrm{I}, \mathrm{III}, 19$.

19 Libro I de la Política.

20 De Regimine principum, Opúsculo 20, Libro 1, Cap. I.

${ }^{21} \mathrm{DL} I I I, I .2$.

${ }_{22} \mathrm{DL}$ III,I,4. Suárez cita al Sabio: Donde no hay gobierno va el pueblo a la ruina. (Prov. II).

${ }^{23} \mathrm{DL} \mathrm{III,III,2.}$
} 
pone la forma dando el poder. ${ }^{24}$ Esta misma es la opinión de diversos autores con los que Suárez coincide y que menciona expresamente a saber: Tomás de Vio, Covarrubias, Vitoria y Soto. ${ }^{25}$ Seguidamente el Doctor Eximio argumenta a favor de su tesis diciendo que, una vez que se ha formado la comunidad, le sigue naturalmente la formación de un poder que dicte leyes y que ello no puede ser de ningún modo impedido por el hombre. De este modo nos quiere indicar que si no está en el hombre impedir que se forme este poder es porque el mismo no deriva directamente del hombre, sino de Dios. Por ello expresa: "supuesta la decisión de los hombres de reunirse en una comunidad política, no está en sus manos el impedir esta jurisdicción; luego es señal de que no proviene a las inmediatas de su voluntad como de verdadera causa eficiente". ${ }^{26}$ Lo que aquí nos interesa reafirmar es que en Suárez, en última instancia, Dios es la causa eficiente del poder. La confirmación de esta idea la encuentra Suárez en aquel pasaje bíblico que afirma: No hay potestad que no venga de Dios y quien resiste a la potestad, resiste a la ordenación de Dios. ${ }^{27}$ La diferencia con el modo de pensar moderno radica en que, en última instancia, no se prescinde en Suárez de la idea de un Dios que regula en forma activa a través de sus leyes y que las transmite a la autoridad humana. Así pues, el acto de desobediencia a la "verdadera" ley constituye en último instancia un acto de desobediencia a Dios.

\footnotetext{
24 Ibídem. "hanc potestatem dari immediate a Deo ut auctore naturae".

${ }^{25}$ Esta misma idea se encuentra en DL III,III, 4: este poder proviene de dios como su autor primero y principal. Este mismo sentido que encontramos en DL III,III, 2 y 4 lo observamos igualmente en el Defensio Fidei III,I,6. Allí sostiene Suárez: el poder del principe político proviene de Dios. Ahora bien, al igual que como el Eximio afirma en De legibus, lo que nos permite deducir que su planteo no se vio forzado por la necesidad de oponerse el despotismo de Jacobo I, sostiene Suárez que "la soberanía civil Dios la da inmediatamente sólo a la comunidad perfecta" -DF III,II,5-. En este sentido adhiere el Doctor Eximio al cardenal Bellarmino según el cual a los reyes la autoridad no se la concedió Dios inmediatamente como se la concedió a los papas (Conf. DF III,II,1). De acuerdo con estas ideas afirma Suárez que "puede afirmarse que la autoridad política viene inmediatamente de Dios, y que sin embargo, a los reyes y corporaciones soberanas se la han entregado inmediatamente no Dios sino los hombres" DF III,II,4 in fine-. De este modo tanto en De legibus como en Defensio Fidei se destaca, y es lo que aquí nos interesa, que el poder proviene, en última instancia, de Dios. Así pues Suárez, como afirma Francisco Alvarez en su introducción al defensio Fidei, " se halla equidistante entre el absolutismo imperante en su tiempo y el contractualismo posterior". "todos los reyes absolutistas se creían investidos de la autoridad inmediatamente por Dios" ( ej. Jacobo I). Por el contrario los contractualistas posterioresHobbes, Locke, Rousseau, prescindirán de Dios y de la naturaleza, para concretar la autoridad como la suma de las voluntades individuales. ( $\mathrm{p} . \mathrm{XXVI}$ ).

${ }^{26} \mathrm{DI} I \mathrm{II}, \mathrm{III}, 2$.

${ }_{27}$ San Pablo Rom. 13 "Non est potestas nisi a Deo, et qui potestate resistit, Dei ordinationi resistit".
} 


\section{4 ¿Existe posibilidad de desobediencia a la ley humana en Suárez? En caso afirmativo, ¿Cuáles son los motivos?}

Una vez que se ha destacado la importancia de la autoridad y del poder de dar leyes, corresponde analizar si existe en nuestro autor la posibilidad de desobediencia a la ley humana.

Hemos afirmado que el tema propuesto en este trabajo no fue estudiado en forma minuciosa por nuestro autor en el De Legibus. Sin embargo, del análisis de otras cuestiones resulta posible inferir que efectivamente Suárez admitió la posibilidad de desobediencia a la ley humana.

Adquiere particular interés para el investigador constatar, como acabamos de afirmar, que Suárez no haya tratado en un capítulo especial la cuestión de la desobediencia a la autoridad y a la ley y, al mismo tiempo, haya dedicado expresamente en el libro tercero capítulos enteros a otras cuestiones $^{28}$ que en apariencia resultarían de menor importancia que la que aquí se estudia.

Hemos dicho que este trabajo se encuadra dentro de otro mayor como lo es analizar el pensamiento de Suárez a los efectos de realizar de algún modo nuestra valoración sobre el lugar que ocupa Suárez dentro de la historia. Algunos autores como Bastit ${ }^{29}$ encuentran en nuestro autor una fuerte identificación con el pensamiento de la modernidad. Sin embargo, en esta cuestión creemos que Suárez se muestra fiel seguidor del pensamiento clásico. Ello lo veremos a continuación, en relación con diversas razones por las que en Suárez existe la posibilidad de desobediencia a la autoridad y a la ley humana.

Debemos en primer lugar considerar, como afirma nuestro autor en De legibus I,XIII,1, las causas de la ley que fueran puestas por Tomás de Aquino y a quien expresamente sigue Suárez. Al respecto sostiene el Doctor Eximio que la Causa Eficiente de la ley es que provenga de quien tiene poder y jurisdicción. La Causa Material objetiva es que debe tratar de una cosa

\footnotetext{
${ }^{28}$ Sólo a título de ejemplo mencionamos el capítulo XIV del libro tercero en el que Suárez trata sobre si pueden ser materia de la ley humana los actos ya pasados.

${ }^{29}$ Puede observarse ello en su libro El nacimiento de la ley moderna especialmente en la tercera parte de la misma en la que se dedica al tema de la ley en Suárez.
} 
honesta y referirse a los súbditos y la Causa Final es que la ley debe darse para el Bien Común. Estas tres causas de la ley adquieren importancia en cuanto a la cuestión de la obediencia o no a la ley positiva humana.

Trataremos a continuación en forma más detallada la cuestión de la desobediencia en relación con estas tres causas de la ley.

La primera razón para poder desobedecer la ley se produce en el caso de que quien la dicte carezca de poder y jurisdicción para ello. De esta cuestión se ocupa Suárez cuando analiza el derecho de resistencia al tirano y también en DL I,VIII. En este sentido coincide con el Aquinate en cuanto "el hombre debe obedecer a los príncipes y gobernantes según lo requiere el orden de la justicia, que no se salva cuando la autoridad no es justa, sino usurpada, o si manda cosas contrarias al derecho, en estos casos no se les debe obedecer" ${ }^{30}$ El Doctor Eximio se detiene en esta cuestión cuando en el cap. VIII del libro 1 se plantea si requiere la ley que se dé con autoridad pública. Se refiere aquí nuestro autor a la causa eficiente de la ley. Suárez cita en primer lugar a Tomás de Aquino quien se pregunta si en realidad quien hace la ley es la razón de cada uno - I-II q.90 a.3-. Y en este sentido afirma Suárez que parece que la razón de cada uno tiene fuerza de ley al menos tratándose de los dictámenes de la ley natural. luego no se requiere que la dé el poder público. El Doctor Eximio quiere afirmar aquí que la ley natural impone por sí sola una imperatividad sin necesidad de un poder público. En efecto, sostiene que: "Sin intervención de poder alguno superior, las leyes de honrar a los padres, de no mentir y otras semejantes obligan siempre, luego esa condición no es esencial a la ley”. Así pues, podría parecer entonces que la sola razón, pudiendo determinar lo que manda la ley natural, sería suficiente sin necesidad de que mande algo la autoridad pública. Sin embargo, ello no es de ese modo. Aun cuando se destaca la importancia de la ley natural, la posibilidad de la razón de descubrimiento de esta ley y la consideración de la ley humana como una determinación de aquella, realizada por los hombres prudentes, se requiere necesariamente que la ley provenga de la autoridad pública. Ahora bien, la pregunta es ¿por qué se requiere la promulgación por parte de la autoridad pública? Suárez responde efectuando una diferenciación entre los actos de pedir, prometer y mandar. Así pues, en el acto de mandar "por el precepto, el que manda obliga al otro a quien manda, y por eso es necesario que tenga derecho y poder superior

${ }^{30}$ Tomás de Aquino. S.Th. II-II Q.104 a.6 ad. 3. 
sobre él" ${ }^{31}$ La razón que esgrime el Doctor Eximio es que: no todo hombre puede mandar a otro, ni un igual puede obligar a un igual, como es evidente, porque no existe ninguna razón para que uno esté obligado a obedecer al otro más que éste a él. Luego se necesita un especial poder superior para mandar válida y eficazmente. Existe aquí una combinación de conceptos que resulta relevante destacar. En primer lugar, señala Suárez una primera condición que es que quien mande tenga autoridad para mandar. En ello sigue nuestro autor a Tomás de Aquino - I-II q.90 a.3- a quien cita en DL I,VIII,2. Es decir, se requiere necesariamente que para mandar a quien en principio es "un igual", se reciba un poder que lo coloque en una posición de superioridad por sobre el igual. De allí la importancia de la autoridad pública. Pero, a su vez, ese poder de jurisdicción debe reunir una segunda cualidad y es que persiga el bien de la comunidad. Debe advertirse que se entrelazan aquí la causa eficiente y la causa final de la ley. Ello demuestra indudablemente la importancia que tiene para Suárez la idea de bien común, destacada en DL I,VII,1. En efecto, señala el Doctor Eximio: "El poder de jurisdicción se concede para el bien de la comunidad". ${ }^{22}$ Esta misma idea la reitera nuestra autor en otro pasaje en el cual destaca nuevamente la idea de bien común y que sirve a modo de confirmación de tesis de que, el poder de jurisdicción y la facultad de crear leyes, deben tener por fin principal la realización de aquél bien: "La creación de leyes es el principal acto con el que se gobierna el estado y que, por consiguiente debe tener por fin el bien común; luego de suyo pertenece al poder de gobierno del estado, al cual toca procurar el bien común de éste”. ${ }^{33}$ La importancia que otorga Suárez a la autoridad es tal que destaca que no sólo basta que sea justa la acción prescrita para que sea propiamente obligatoria la ley, ni basta que la misma sea dada por la prudencia de los sabios, sino que se exige que los mismos tengan a su vez el poder para dar leyes. Así pues afirma el Doctor Eximio: "Sólo la rectitud o justicia de la acción prescrita por la ley no basta para que una ley sea propiamente obligatoria, y por eso, aunque en la formación de las leyes es necesaria la prudencia y deben y suelen intervenir los consejos de los sabios, sin embargo esos consejos no bastan si falta la voluntad de quien tenga poder, poder y voluntad de los cuales la ley recibe la fuerza y el ser de ley". ${ }^{34}$

\footnotetext{
${ }^{31} \mathrm{DL} I, \mathrm{VIII}, 3$.

${ }^{32} \mathrm{DL} I, \mathrm{VIII}, 5$.

${ }^{33} \mathrm{DL} \mathrm{I}, \mathrm{VIII}, 7$.

${ }^{34} \mathrm{DL}$ I,VIII,10.
} 
Puede decirse que estas tres causas, eficiente, material y final permanecen siempre juntas en el desarrollo de esta cuestión por parte de Suárez. En efecto, en el Cap. XXXI del libro tercero del De legibus trata nuevamente el Doctor Eximio la cuestión de la obligatoriedad de la ley al afirmar que no se debe obedecer a la ley cuando es contraria a Dios. Así pues afirma: No les obedezcamos - a los hombres- en aquello que son contrarios a Dios ni antepongamos su servicio al servicio de Dios. En cambio quien se somete a una ley humana que esté dada con poder justo y legítimo, más sirve a Dios que al hombre, porque el hombre da la ley únicamente como ministro de Dios, y Dios mismo manda obedecer a los príncipes y superiores. ${ }^{35}$

Resumiendo, podemos decir que la obligatoriedad de la ley humana existe sólo cuando se cumplen las propiedades señaladas para la ley entre las que se destacan que la misma sea dada por una autoridad pública, que sea justa, y dirigida al bien común. Esto lo confirma Suárez al afirmar que "cada ley humana obliga a todas las personas que son miembros de la comunidad para la cual se da la ley, supuestas las demás condiciones necesarias. Digo esto último porque en la ley se deben suponer todas las otras condiciones que se requieren para que la ley obligue. ${ }^{36}$

Una segunda razón que permite la desobediencia se encuentra en el caso de una ley injusta. Ello tiene que ver con la causa material objetiva de la ley. Indudablemente Suárez tiene presente aquí las propiedades de la ley enumeradas por Isidoro de Sevilla ${ }^{37}$ y que cita expresamente en DL I,IX,1.

En lo que se refiere a la "ley injusta” Suárez es fiel seguidor del pensamiento clásico en cuanto al igual que Aristóteles, Cicerón, Agustín de Hipona, Isidoro de Sevilla y Tomás de Aquino sólo podrá llamarse ley aquella que sea justa. ${ }^{38}$ Como ya explicamos a estos autores, a los que adhiere Suárez, los une la idea de una identificación entre el derecho y la justicia. No existe separación entre estos conceptos como lo sostiene el pensamiento jurídico moderno. El derecho para ser derecho y ser aplicado y obedecido debe ser justo, de lo contrario no es derecho. El pensamiento moderno, por el contrario, sostiene que puede haber derecho aun cuando el mismo resulte

\footnotetext{
${ }^{35} \mathrm{DL} I \mathrm{II}, \mathrm{XXXI}, 2$.

${ }^{36} \mathrm{DL}$ III,XXXI,6.

${ }^{37}$ Isidoro de Sevilla. Etimologías, Madrid. ed. Bac, 1982. L, 5, c. 21 y L.2, cap. 10. "La ley será honesta, justa, posible, conforme a la naturaleza, conforme a la costumbre de la patria, adaptada al tiempo y al lugar".

${ }^{38}$ Entre otros lugares el tema es tratado por Suárez en DL I,IX,2 y I,XI,3.
} 
injusto. Este pensamiento se refleja, por ejemplo, en las obras de Kelsen. ${ }^{39}$ Resulta clara en los autores clásicos la identificación entre el derecho y lo justo. La conocida afirmación "non videtur esse lex quae iusta non fuerit" 40 caracteriza a los autores recientemente mencionados incluido, claro está, Suárez. En otras palabras ello quiere decir que la mención de una disposición como ley supone la noción de justicia. En relación con el tema que nos ocupa apropiadamente algunos autores han señalado una particularidad en Tomás de Aquino y una controversia sobre la cuestión de si las leyes que son injustas se llaman o no ley. Así pues, se ha afirmado que de acuerdo al planteo del Aquinate en la I-II q.96 a.4 "se produce de hecho, en la historia de la iusfilosofía, un punto de inflexión que viene a poner las cosas en su lugar, en el sentido más realista del término: existen leyes justas, y también pueden existir leyes injustas...La cuestión, sin embargo, se encuentra sujeta a discusión, y ello se debe a que en otros pasajes de sus obras, Santo Tomás parece seguir la vertiente agustiniana, cuando el hiponense afirmaba que la ley injusta no era ley". ${ }^{41}$ Uno de estos pasajes, en apariencia contradictorio, se encuentra en la I-II q. 95 a.2 en el cual el aquinatense afirma que "toda ley humana tendrá carácter de ley en la medida en que se derive de la ley de la naturaleza; y si se aparta en un punto de la ley natural, ya no será ley, sino corrupción de la ley". ${ }^{42}$ A nuestro entender resulta adecuada la afirmación de que en Tomás de Aquino puede encontrarse un contenido diferente o una particularidad en cuanto efectivamente en la solución de la I-II q.96 a.4 el Doctor Angélico afirma que "las leyes humanas son o justas o injustas". Y en el mismo lugar el Aquinate afirma que "las leyes injustas pueden serlo por dos razones". Sin embargo, creemos que esta posible divergencia es resuelta por el Aquinate en esta misma cuestión al afirmar que las leyes injustas "magis sunt violentiae quam leges", basándose en la citada frase de Agustín de Hipona según la cual "no parece que sea ley la que no es justa”. En relación con lo que analizamos Suárez se pregunta ¿Cuál es la propia y verdadera ley? Allí afirma, siguiendo a Tomás de Aquino, Agustín de Hipona, Cicerón y Platón que "hablando con propiedad, solamente puede llamarse

\footnotetext{
${ }^{39}$ Kelsen H. Teoría Pura del Derecho, Ed. Eudeba, $4^{a}$.ed. $2^{a}$ ed. reimp.- Buenos Aires, año 2003. p. 135 : El derecho debe ser aplicado aun si es juzgado malo.

${ }^{40}$ Agustín de Hipona. Op. cit en nota 5.

${ }^{41}$ Portela. J.G La justificación iusnaturalista de la desobediencia civil y de la objeción de conciencia. Educa, 2005. p. 70.

42 Unde omnis lex humanitus posita intantum habet de ratione legis, inquantum a lege naturae derivatur. Si vero in aliquo a lege naturali discordet, iam non erit lex sed legis corruptio.
} 
ley la que es medida de la rectitud sin más y consiguientemente, sólo la que es regla recta y honesta". ${ }^{43}$ Podemos decir que Suárez resuelve aquella posible discusión a que nos refiriéramos respecto de que Tomás de Aquino, algunas veces, denomina ley a la que es injusta. En este sentido el Doctor Eximio aporta claridad desde que afirma que "la ley injusta no es ley sino que recibe el nombre de ley sólo por cierta analogía en cuanto que prescribe una determinada manera de obrar en orden a un fin". 44 Así pues, si comparamos este pasaje de Suárez con la I-II q.96 a.4 en la que el Aquinate se refiere a la ley injusta como "violencia" y la I-II q.95 a.2 en la que la denomina "corruptio legis", esta discusión se encuentra resuelta, observándose una perfecta continuidad entre el pensamiento de Tomás de Aquino y Suárez. Del planteo del Doctor Eximio se deduce, pues, que no se produce en Tomás de Aquino una ruptura respecto de la doctrina iusnaturalista tradicional, en cuanto la ley injusta no es "propiamente ley". Y, por este motivo, existe también en Suárez continuidad de aquél pensamiento y, por tanto, no se produce una corrección de Tomás de Aquino en lo que respecta a esta cuestión. En otras palabras, el Doctor Eximio no ha interpretado que la afirmación de Tomás de Aquino de que "las leyes humanas puedan ser justas o injustas" 45 signifique la admisión por parte del Angélico de la posibilidad de un "derecho injusto". Estas aclaraciones pueden a primera vista parecer una desviación del tema propuesto. Sin embargo, creemos resulta oportuno no olvidarlas en cuanto para los autores a que nos hemos referido, entre ellos Suárez, la ley ocupa un lugar de privilegio. Para el pensamiento de los filósofos de la antigüedad la ley era algo de la divinidad y concretamente para Agustín de Hipona, Tomás de Aquino y Suárez la ley debe ser una derivación de la ley de Dios. ${ }^{46}$ De allí que, en relación con el tema que tratamos, si toda autoridad proviene de Dios y las leyes propiamente son una derivación de la ley de Dios, admitir la posibilidad de desobediencia requiere como condición "sine qua non" que se determine previamente la injusticia de lo que Suárez entiende que no puede "propiamente llamarse ley".

\footnotetext{
${ }^{43}$ Idem nota 3.

${ }^{44} \mathrm{lb}$.

${ }^{45}$ S. Th. I-II Q.96 a.4.

${ }^{46}$ Un ejemplo que nos demuestra la veneración del hombre antiguo por la ley, que luego también asumió el hombre medieval, lo encontramos en aquella célebre expresión de Leonidas en el desfiladero de las Termópilas: "Caminante, ve a Esparta a decir que aquí hemos muerto por defender sus leyes".
} 
Ahora bien, tratando sobre la cualidad de honesta que debe reunir la ley, conviene explicar con mayor detalle los motivos por los que Suárez cree que tales disposiciones pierden el carácter de ley y, sólo por cierta analogía, se denominan leyes. Una de las razones que expone nuestro autor se encuentra en la posibilidad de error de la voluntad humana y que compara a su vez con la voluntad de Dios. Al respecto afirma el Doctor Eximio: "el legislador humano no tiene una voluntad perfecta como la tiene Dios, y por eso, por lo que toca a él y de hecho, a veces - como es claro-, puede mandar cosas injustas; sin embargo, no tiene poder para obligar con leyes injustas, y por eso, aunque mande cosas injustas, tal precepto no es ley, porque no tiene fuerza ni valor para obligar. Me refiero a una obra injusta contraria a la ley natural o divina" ${ }^{47}$ Resulta interesante observar aquí que Suárez repite prácticamente las mismas palabras que Tomás de Aquino en la respuesta de la I-II q.96 a.4 aunque no cite este pasaje de la Suma Teológica. Lo que nos interesa destacar es que Suárez efectivamente trata sobre la cuestión de la desobediencia a la ley humana. Hemos visto como nuestro autor destaca la importancia de la autoridad como proveniente de Dios. Pero ello no significa que esta autoridad humana sea perfecta y no pueda errar, mandando cosas injustas. A los efectos de mostrar cuan lejano se encuentra Suárez del pensamiento moderno resulta interesante destacar la diferencia que media entre nuestro autor y Hobbes. Para este último, contrariamente al Doctor Eximio, no puede existir una ley que sea injusta. No admite que la autoridad pueda dictar una ley injusta por que parte del presupuesto de una voluntad perfecta. ${ }^{48}$ Para Suárez, por el contrario, puede haber de hecho imperfección en la inteligencia y voluntad humana y luego disposiciones injustas que no obligarán en el foro de la conciencia ${ }^{49}$ en cuanto su injusticia le hace perder el carácter de ley.

\footnotetext{
${ }^{47} \mathrm{DL}$ I,IX,4: "Nam legislator humanus non habet voluntatem perfectam, sicut Deus, et ideo quantum est ex se, et quoad factum potest interdum iniqua praecipere, ut constat; non tamen habet potestatem ad obligandum per iniquas leges, et ideo licet iniqua praecipiat, tale preceptum non est lex, quia vim, aut valorem ad obligandum non habet: loquor autem de opere iniquo, quod sit contra legem naturalem aut divina".

48 Hobbes.T. Leviatán. Hobbes. Thomas. Leviathan. Revised student edition. Edited by Richard Tuck, Cambridge, 2004.Pte II, cap. XXX,182. p.239: But what is a good Law? By a Good Law, I mean not a just Law: for no Law can be injust. The Law is made by the Soveraign Power, and all that is done by such Power, is warranted, and owned by every one of the people.

${ }^{49}$ Sobre la obligatoriedad en conciencia de la ley justa en Tomás de Aquino se encuentra en S.Th I-II q.91 a.3 y q. 95 a.2. En Suárez se trata el tema en DL III,XXI.
} 
La tercera razón por la que se permite la desobediencia a la ley es en el caso que no cumpla la ley con su causa final que es la realización del bien común. Al respecto afirma Suárez: "acerca del fin (de la ley) vale todo lo que se dijo en el capítulo séptimo, en el cual demostramos que no es ley la que no se hace para el bien común". ${ }^{0}$ Por lo que de apartarse de dicho bien pierde tal disposición el carácter de ley. En este aspecto puede verse nuevamente el seguimiento fiel a Tomás de Aquino que sostiene estas mismas ideas en la I-II q. 96 a.4 y a.6.

Suárez ha dedicado el cap. VII del libro I a la cuestión del bien común. Esta propiedad resulta de suma importancia para Suárez en cuanto afirma que "de esta cualidad parecen depender en su mayor parte las otras". 51 Señala el Doctor Eximio que existe coincidencia en los autores en cuanto: a la esencia y sustancia de la ley pertenece el que se dé para el bien común y por él principalmente. Cita Suárez una vez más a Tomás de Aquino - I-II q.90- y también a Aristóteles - Ética a Nicómaco libro 3, cap. 6-; Platón- Diálogo Hippias y libro 1 de las leyes-; y Cicerón- Libro 3 de las leyes- entre otros.

En DL I,VII,4 se refiere concretamente a las razones por las que la ley humana debe perseguir el bien común. Ellas son:

1 Al imponerse las leyes a la comunidad deben darse principalmente por el bien de la comunidad. En otro caso serían desordenadas, pues es contrario a toda rectitud ordenar el bien común al particular.

2 La felicidad del estado es el fin último en su esfera. Luego ese debe ser el primer principio de la ley. Luego la ley debe ser para el bien común.

3 En cuanto al origen de la ley humana el poder se ha dado para el bien común de la comunidad.

Debe advertirse aquí que Suárez distingue entre el poder espiritual que proviene inmediatamente de Dios y el poder "puramente temporal” que es dado inmediatamente por los mismos hombres. Esta doctrina de nuestro autor se complementa con lo que sostiene en DL I,III,17. Allí afirma que el

${ }^{50} \mathrm{DL} \mathrm{I}, \mathrm{IX}, 13$. "Nam de prima procedunt omnia dicta in capite septimo, ubi ostendimus, non esselegem, quae propter commune bonum non fertur.

$51 \mathrm{DL}$ I,VII,1. 
poder del hombre "mediatamente" proviene de Dios cuando sigue el dictamen de la ley eterna o eterna justicia, como refiere Agustín de Hipona ${ }^{52}$ y a quien Suárez cita en DL I,VII,9. En este sentido el poder que es dado "inmediatamente" por los hombres y "mediatamente" por Dios debe ser justo para que pueda existir coincidencia entre el mandato humano y el divino. Así pues, cuando el poder es dado inmediatamente por los hombres como señala Suárez "es evidentísimo que no ha sido dado para utilidad del príncipe sino para el bien común de los que lo han dado". ${ }^{3}$ El Doctor Eximio cita a San Basilio quien afirma: "el tirano se diferencia del rey en que aquél en su gobierno busca su propia utilidad, éste la utilidad común”. Del mismo modo piensan Aristóteles ${ }^{54}$ y Tomás de Aquino. ${ }^{55}$ En este caso se refiere Suárez no al tirano por usurpación del poder sino al que lo es por el modo de ejercerlo en cuanto no persigue el bien común sino su bien particular.

La idea principal que nuestro autor destaca aquí es, siguiendo al Aquinate I-II q.90 a.2 y Agustín de Hipona - De civitate dei L. 19, cap. 16-, la ordenación de la parte al todo, del bien particular al bien común. El pensamiento de Suárez se resume en que: El bien común se prefiere al privado cuando no pueden darse juntos. ${ }^{56}$ En virtud de ello es que sostiene, refiriéndose al tributo injusto y tiránico, que no es ley: si el tributo fuese injusto y tiránico, entonces no sería ley sino que sería a manera de un privilegio injusto. ${ }^{57}$ Así pues, para ser verdadera ley debe mirar al bien común ya que tal es la finalidad por la que se impone el tributo. En efecto, para ser verdaderas leyes, deben mirar al bien común, ya que los tributos no se dan al rey si no es en cuanto persona común y pública, y para que use de ellos para el bien común“. ${ }^{58}$ De este modo la injusticia de la ley, en el caso de que no atienda principalmente al Bien Común, le hace perder en realidad el carácter de ley. De ese modo no existirá el deber de obedecer aquello que no es "verdadera ley".

\footnotetext{
52 Op. cit. en nota 5.

$53 \mathrm{DL} \mathrm{I}, \mathrm{VII}, 5$.

${ }^{54}$ Aristóteles. Éthic a Nicomaque. Traducción de J. Tricot, Paris, 1990 VIII,12, 1160 b. La Polítique I. Traducción de J. Tricot, Paris, 1989, III,7, 1279 b 6; IV,10,1295 a 19; V,10,1311 a 2

${ }_{55}$ S.Th. II-II q. 42 a.2 ad 3 y De Reg. Principum L.3, cap. 11.

${ }^{56} \mathrm{DI}$ I,VII,14: "Commune bonum praefertur privato, quando simul esse non possunt".

${ }^{57} \mathrm{DL}$ I,VII,11. "Si autem tributum esset iniustum, et tyrannicum, tunc non esset lex.

${ }^{58} \mathrm{DL} \mathrm{I}, \mathrm{VII}, 13$. Tamen ut verae leges sint, commune bonum respicere debent, quia non dantur Regi, nisi quatenus persona communis, et publica est, et ut in commune bonum illis utatur.
} 
Una cuarta razón por la que se permite en Suárez la desobediencia a la ley humana la encontramos en el segundo párrafo de este apartado 4 del libro 1, capítulo once. Puede verse allí como el Eximio destaca la existencia de una jerarquía entre la autoridad divina y humana. En este sentido nuevamente resulta indudable el distanciamiento de Suárez respecto de la modernidad. Podemos decir que analiza aquí el jesuita granadino lo que el Aquinate trata en la parte final de la respuesta a la I-II q.94 a.4 relacionado con la disposición que atenta contra la autoridad divina. Esto lo explica el Doctor Eximio del siguiente modo. Todo poder viene de Dios. Luego las cosas dadas por Dios se han dado para bien y para edificación y no para mal y destrucción. De este modo ningún inferior puede obligar en contra de la ley y de la voluntad de su superior". Así pues la ley que manda una acción mala va contra la ley de Dios que la prohibe, luego no puede obligar, porque es imposible que los hombres - a un mismo tiempo- se vean obligados a hacer y a no hacer algo. Y si la acción mala está prohibida por ley divina, la ley del inferior no puede suprimir la obligación que impuso el superior" ${ }^{59}$ Resulta interesante destacar en Suárez, como dijimos, esta relación no sólo entre la autoridad divina y la humana sino también en las leyes que ambas dictan. Claramente se deduce la inexistencia de obligatoriedad de la ley humana cuando se opone a la ley divina. En el mismo sentido puede decirse que "la ley del superior", que en este caso es la ley de Dios, no se encuentra para Suárez en un "mundo" ajeno al hombre o que éste no deba en absoluto considerar. Por el contrario, remarca Suárez la presencia e influencia de las leyes divinas en la elaboración de la ley humana. Si bien como el Doctor Eximio afirma la ley humana ha sido compuesta e impuesta por los hombres inmediatamente $^{60}$, para ser ley, mediatamente debe ser una derivación de la ley eterna dada por Dios. En este sentido se comprende la cita de Suárez a Agustín de Hipona en cuanto: "quien da leyes temporales, si es bueno y prudente consulta a la ley eterna para distinguir - según sus reglas inmutables- lo que se debe evitar y lo que se debe mandar en cada circunstancia”. ${ }^{61}$ En este caso existe una concreta obligación y no ya facultad de desobediencia, de acuerdo con la diferenciación que efectúa Tomás de Aquino en la I-II q.96 a.4. Al igual que el Aquinate, quien en el artículo

\footnotetext{
${ }^{59} \mathrm{DLI}, \mathrm{XI}, 4$.

${ }^{60} \mathrm{DL}$ I,III,17: Dicitur ergo humana lex, quia proxime ab hominibus inventa, et posita est.

${ }^{61}$ Agustín de Hipona. De Vera Religione. Cap. 31: "Conditor tamen legum temporalium, si vir bonus est et sapiens, illam ipsam consulit aeternam...
} 
recién citado de la Suma Teológica distingue entre una facultad y una obligación de desobediencia trata Suárez de un caso en el que la desobediencia resulta obligatoria. En este aspecto se percibe nuevamente la sintonía entre el pensamiento del Doctor Eximio y del Aquinate. Así pues, la cuestión que Tomás trata en el final de su respuesta a la cuestión citada a saber, la obligación de desobediencia cuando se atenta contra el bien divino, se encuentra en Suárez en el De legibus en el libro tercero, cuestión treinta y uno, apartado dos. Allí, a propósito de la obligatoriedad de la ley humana, sostiene Suárez que no se debe obedecer la ley humana cuando la misma atenta contra Dios. Las palabras de Suárez se refieren exclusivamente aquí a la ley creada por el hombre: "No les obedezcamos en aquello en que son contrarias a Dios ni antepongamos su servicio al servicio de Dios. En cambio quien se somete a una ley humana que esté dada con poder justo y legítimo, más sirve a Dios que al hombre, porque el hombre da la ley únicamente como ministro de Dios, y Dios mismo manda obedecer a los príncipes y superiores". Este pasaje de Suárez resulta sumamente interesante en cuanto en el mismo se encuentran diversos conceptos claves de su pensamiento. El pasaje citado de la Suma Teológica y esta cuestión en Suárez coinciden en cuanto la desobediencia se transforma en exigencia cuando la ley atenta contra Dios o el bien divino. Puede decirse que ambos coinciden en cuanto "obedire oportet Deo magis quam hominibus". Es decir "resulta necesario obedecer más a Dios que a los hombres". Pero, por otra parte, remarca nuestro autor que si la ley humana no atenta contra Dios y reúne los demás requisitos que se exigen para la ley, y que explicó en el libro 1 del De legibus, existe una verdadera obligación en conciencia de obedecer esa ley humana. Debe advertirse que al igual que en la doctrina del Aquinate ${ }^{62}$ deben ser graves razones las que permitan la desobediencia y aún así deberá analizarse con suma prudencia la posibilidad de practicarla. Ello porque la autoridad que dicta la ley, tanto para Tomás de Aquino como para Suárez, recibe esa potestad directamente de Dios. De este modo la ley humana es "inmediatamente" una ley dictada por el hombre pero "mediatamente" se encuentra o debe encontrarse la ley divina tras ella, como señala el Eximio en DL I,III,17.

62 S.Th. respuesta de la I-II Q. 96 a.4. 


\section{Conclusión}

A partir de los aspectos analizados en los diversos puntos de este trabajo creemos puede afirmarse que en Suárez son 4 los motivos por los que existe posibilidad de desobediencia a la disposición injusta.

Al respecto resulta fundamental la consideración de las causas de la ley que enumera Suárez en De legibus I,XIII,1 siguiendo una vez más a Tomás de Aquino.

Así pues a los efectos de nuestro trabajo destacamos:

1 La causa eficiente. La ley debe haber sido dada por quien tiene poder y jurisdicción.

2 La causa material objetiva. La ley debe tratar de una cosa honesta y referirse a los súbditos.

3 La causa final. La ley debe darse para el Bien Común.

El primer motivo por el que existe posibilidad de desobediencia se encuentra en el hecho de que haya sido dada por quien no tiene poder $y$ jurisdicción. Es decir por quien no tiene autoridad pública. Ahora bien ¿por qué se requiere que la ley se dé con autoridad pública? Suárez responde realizando una diferenciación entre los actos de pedir, prometer y mandar. Así pues, en el acto de mandar "por el precepto, el que manda obliga al otro a quien manda, y por eso es necesario que tenga derecho y poder superior sobre él”. ${ }^{63}$ La razón que arguye el Doctor Eximio es que: no todo hombre puede mandar a otro, ni un igual puede obligar a un igual, como es evidente, porque no existe ninguna razón para que uno esté obligado a obedecer al otro más que éste a él. Luego se necesita un especial poder superior para mandar válida y eficazmente. Ese poder de jurisdicción sostiene el Doctor Eximio "es para el bien de la comunidad". ${ }^{64}$ La autoridad y de allí el poder para crear la ley resulta fundamental. En este sentido no sólo basta que sea

\footnotetext{
${ }^{63} \mathrm{DL} \mathrm{I}, \mathrm{VIII}, 3$.

64 DL I,VIII,5: "Posterior autem potestas per se, et ex primera institutione sua est propter bonum communitatis, in quam datur..."
} 
justa la acción prescrita para que sea propiamente obligatoria la ley, ni basta que la misma sea dada por la prudencia de los sabios. Se exige también que los mismos tengan a su vez el poder para dar leyes.

El segundo motivo se produce cuando se incumple con la causa material objetiva de la ley. Es decir, cuando la ley no es justa. Al respecto vimos que Suárez se pregunta ¿Cuál es la propia y verdadera ley? Y su respuesta, coherente con el pensamiento jurídico clásico, es que sólo puede llamarse ley la que es justa. La "ley injusta" sólo recibiría el nombre de ley por cierta analogía, en cuanto ordena algo. Pero lo que se ordena debe ser justo para ser verdadera ley.

Las razones por las que existirá esta posibilidad de desobediencia a la disposición injusta nos permitirán una vez más evitar la inapropiada calificación como moderno que, para algunos, pesa sobre Suárez. En este sentido el Doctor Eximio sostiene que la voluntad humana puede errar a diferencia de la voluntad divina. Ello porque sólo la voluntad divina es perfecta. No así la humana. Por esta razón es natural que pueda el hombre errar o caer en imprecisiones. Lo que no sería natural es que las leyes injustas, producto de esa voluntad e inteligencia imperfecta, obliguen. Cuando lo que se manda es injusto se produce instantáneamente la pérdida de la fuerza y el valor para obligar como ley.

El tercer motivo que permite la desobediencia se produce en el caso de que no cumpla la ley con su causa final a saber, la realización del bien común. Es esta última una propiedad fundamental en Suárez aun cuando llamativamente no la menciona en su definición de ley. Sin embargo, no puede dudarse del lugar relevante que posee para el Doctor Eximio en cuanto afirma que "de esta cualidad parecen depender en su mayor parte las otras".

Un cuarto motivo por el que se permite en Suárez la desobediencia a la normativa injusta se produce cuando existe oposición entre la autoridad divina y la humana. Como hemos podido ver ninguna ley de un inferior puede ir en contra de una ley de un superior. Ello en cumplimiento del conocido principio del derecho según el cual lex superior derogat inferiori. De este modo, siendo Dios el supremo legislador, ninguna ley puede ser contraria a sus leyes. En ese caso tales disposiciones injustas perderán el carácter de ley en cuanto existirá primero la obligación de obedecer la ley divina. En este caso no hablamos de posibilidad de desobediencia sino de obligación. El servicio de Dios, en palabras del propio Suárez, exige obediencia sólo a la ley que es justa ya que, sólo en ese caso, existe 
continuidad entre la ley divina y la humana. En este sentido para el Doctor Eximio resulta del mismo modo grave obedecer una ley que atenta contra el bien divino como desobedecer una ley que es justa en cuanto, de reunir tal cualidad, representa un reflejo de la sabiduría y voluntad de Dios que se manifiesta por medio de la autoridad humana.

Así pues, en el pensamiento de nuestro autor no se debe siempre una obediencia ciega a la autoridad, como sería en el modelo de Hobbes, sino sólo cuando la delegación divina se refleja en la ley justa. Aplicado a nuestros tiempos, podría decirse que existe una notable diferencia entre el pensamiento actual y el del jesuita granadino para quien, siguiendo a Tomás de Aquino, la regla sigue siendo la obediencia a la autoridad y la excepción, luego de prudente análisis, la desobediencia. Estos términos probablemente se han invertido en los tiempos modernos por motivos que no resulta apropiado tratar aquí, de tal forma que la regla parece ser la desobediencia y el cuestionamiento a la autoridad. La excepción será la obediencia, luego del prudente análisis del destinatario de la norma. El pensamiento de Suárez, como señalamos, se encuentra en este sentido notablemente alejado del moderno y, por el contrario, se muestra fiel seguidor del pensamiento antiguo y medieval en cuanto a la obediencia a la autoridad.

Puede decirse, en definitiva, que Francisco Suárez ha tratado la posibilidad de desobediencia a la disposición injusta aunque no haya dedicado en el De legibus un capítulo especial a la cuestión. Decimos disposición y no ley injusta en cuanto, en continuidad con el pensamiento clásico, la ley sólo será ley cuando presente la cualidad de justa. En caso contrario no será ley y existirá posibilidad de desobediencia en cuanto no estaremos en presencia de una ley.

E-mail: sebapier@hotmail.com

Rcebido: março/2009

Aprovado: julo/2009 